\title{
FECUNDIDADE E PREFERÊNCIA ALIMENTAR DE FÊMEAS OVÍGERAS DO CAMARÃO DE ÁGUA DOCE MACROBRACHIUM JELSKII (MIERS, 1877) (DECAPODA, CARIDEA, PALAEMONIDAE) EM UMA LAGOA ARTIFICIAL URBANA NA BACIA HIDROGRÁFICA DO RIO PARNAÍBA
}

\author{
Silva, G.P.B. ${ }^{1,}$; Amorim, A.K.M² \& Pralon, B.G. ${ }^{3}$ \\ ${ }^{1}$ Universidade Federal do Piauí, Departamento de Biologia, campus Universitário Ministro Petrônio Portella, CEP: \\ 64049-550, Teresina, PI. E-mail: \\ ${ }^{2}$ Universidade Federal do Piauí, Departamento de Biologia, campus Universitário Ministro Petrônio Portella, CEP: \\ 64049-550, Teresina, PI. \\ ${ }^{3}$ Universidade Federal do Piauí, Departamento de Biologia, campus Universitário Ministro Petrônio Portella, CEP: \\ 64049-550, Teresina, PI, Brasil.
}

*Autores correspondentes: guilherme.paulo43@gmail.com; andressa-kelly1995@hotmail.com

O camarão de água doce Macrobrachium jelskii (Miers, 1877) é largamente distribuído em regiões tropicais e subtropicais, em ambientes lênticos e lóticos. Aspectos ecológicos de populações desta espécie na bacia hidrográfica do Rio Parnaíba são praticamente desconhecidos. O presente trabalho teve o objetivo de caracterizar a fecundidade da população proveniente de uma lagoa localizada na zona urbana de Teresina, capital do Estado do Piauí, Brasil, bem como verificar a preferência alimentar por parte das fêmeas ovígeras. As amostras foram coletadas de setembro a novembro de 2017, no Parque Lagoas do Norte, utilizando armadilhas contendo dois tipos de iscas: peixe e "ralão de coco babaçu". Do total de 963 espécimes amostrados, 62 (6,44\%) eram fêmeas ovígeras. A média do comprimento do cefalotórax e peso destas foi, respectivamente, 6,69 1,07 mm e 0,23 \pm 0,12 g. A fecundidade média foi de 49,03 $\pm 40,51$ ovos por fêmea. O volume médio dos ovos foi significativamente maior em fêmeas em fase final do desenvolvimento embrionário ( $p<0,01$ ), e sua média foi de $0,16 \pm 0,06 \mathrm{~mm}^{3}$. As relações número de ovos/comprimento da carapaça e número de ovos/peso apresentaram correlação positiva significativa $(p<0,01)$. Não foi verificada preferência por um tipo de isca por parte das fêmeas ovígeras, o que pode ser explicado pela busca por refúgio no interior das armadilhas ao invés de recurso alimentar pelas mesmas.

Palavras-chave: camarão dulcícola, iscas, ovos, desenvolvimento embrionário. 